\title{
Schizophrenia polygenic risk score influence on white matter microstructure
}

\author{
Beatriz Simões $^{\mathrm{a}}$, Evangelos Vassos ${ }^{\mathrm{b}}$, Sukhi Shergill ${ }^{\mathrm{c}}$, Colm McDonald ${ }^{\mathrm{d}}$, Timothea Toulopoulou ${ }^{\mathrm{c}, \mathrm{e}, \mathrm{f}}$, \\ Sridevi Kalidindi ${ }^{\mathrm{c}, g}$, Fergus Kane ${ }^{\mathrm{c}}$, Robin Murray ${ }^{\mathrm{c}}$, Elvira Bramon ${ }^{\mathrm{c}, \mathrm{h}}$, Hugo Ferreira ${ }^{\mathrm{a}}$, \\ Diana Prata ${ }^{a, i, j, *}$ \\ ${ }^{a}$ Instituto de Biofísica e Engenharia Biomédica, Faculdade de Ciências, Universidade de Lisboa, Portugal \\ ${ }^{\mathrm{b}}$ Social, Genetic and Developmental Psychiatry Centre, Institute of Psychiatry, Psychology and Neuroscience, King's College London, UK \\ ${ }^{\mathrm{c}}$ Department of Psychosis Studies, Institute of Psychiatry, Psychology \& Neuroscience, King's College London, London, UK \\ ${ }^{\mathrm{d}}$ Centre for Neuroimaging \& Cognitive Genomics (NICOG), NCBES Galway Neuroscience Centre, National University of Ireland Galway, Ireland \\ ${ }^{\mathrm{e}}$ Department of Psychology, The University of Hong Kong, Hong Kong Special Administrative Region, China \\ ${ }^{\mathrm{f}}$ Department of Psychology, Bilkent University, Turkey \\ ${ }^{g}$ South London and Maudsley NHS Foundation Trust, London, UK \\ ${ }^{\mathrm{h}}$ Mental Health Neurosciences Research Department, Division of Psychiatry, University College London, London, UK \\ ${ }^{i}$ Department of Neuroimaging, Institute of Psychiatry, Psychology \& Neuroscience, King's College London, London, UK \\ ${ }^{\mathrm{j}}$ Instituto Universitário de Lisboa (ISCTE-IUL), Centro de Investigação e Intervenção Social, Lisboa, Portugal
}

\section{A R T I C L E I N F O}

\section{Keywords:}

Polygenic risk score

PRS

Schizophrenia

Bipolar disorder

White matter

Diffusion tensor imaging

Psychosis

Fractional anisotropy

Mean diffusivity

GWA

Genome-wide association

\begin{abstract}
A B S T R A C T
Schizophrenia (SZ) and bipolar disorder (BD) are highly heritable, share symptomatology, and have a polygenic architecture. The impact of recent polygenic risk scores (PRS) for psychosis, which combine multiple genomewide associated risk variations, should be assessed on heritable brain phenotypes also previously associated with the illnesses, for a better understanding of the pathways to disease. We have recently reported on the current SZ PRS's ability to predict 1st episode of psychosis case-control status and general cognition. Herein, we test its penetrance on white matter microstructure, which is known to be impaired in SZ, in BD and their relatives, using 141 participants (including SZ, BP, relatives of SZ or BP patients, and healthy volunteers), and two white matter integrity indexes: fractional anisotropy (FA) and mean diffusivity (MD). No significant correlation between the SZ PRS and FA or MD was found, thus it remains unclear whether white matter changes are primarily associated with SZ genetic risk profiles.
\end{abstract}

\section{Introduction}

Schizophrenia (SZ) and bipolar disorder (BD) overlap in symptomatology, are both highly heritable, share genetic susceptibility, and their etiology is still little understood (Craddock and Owen, 2005). In a standard genome-wide association approach (GWAs), the SZ Psychiatric Genomic Consortium-2 (PGC2) meta-analysis found 108 genetic variants to be independently associated with SZ (Ripke et al., 2014), each showing a 1-2 odds ratio. Complementarily, one can examine disorder prediction by summarizing variation across all the associated at various levels of significance loci into a quantitative score, i.e. a polygenic risk score (PRS) (Ripke et al., 2014). Using this approach, we have recently reported the PGC2-SZ PRS to explain $9.2 \%$ of SZ case-control variance in a sample of first episode psychosis (Vassos et al., 2017) and $2.7 \%$ of general cognitive ability (Toulopoulou et al., 2019).
Reduced fractional anisotropy (FA) and increased mean diffusivity (MD) in white matter, with heritability ranging $30-82 \%$, except in the fornix where it is untypically low (Vuoksimaa et al., 2017), have consistently been reported in SZ and, to a lesser extent, in BD patients, in studies employing Tract Based Spatial Statistics (TBSS) (Ambrosi et al., 2013; Hummer et al., 2016; Kanaan et al., 2017; Subramaniam et al., 2017; Viher et al., 2016; Zhuo et al., 2016). While a unipolar depression PRS has been negatively associated with FA (a proxy for white matter microstructure integrity) in depression and health $(\mathrm{N}=132)$ (Whalley et al., 2013), no association was found between SZ, a BD or a unipolar SZ PRSs and white matter microstructure, in a study using the UK Biobank data $(\mathrm{N}=816)$ (Reus et al., 2017). However, the UK Biobank study, although powerful, has mixed patients of indiscriminate types, healthy individuals and those without clinical records, which prevented the examination of diagnosis by PRS interactions on brain structure, or

\footnotetext{
* Corresponding author. Instituto de Biofísica e Engenharia Biomédica, Faculdade de Ciências, Universidade de Lisboa, Campo Grande 016, 1749-016, Lisboa, Portugal.

E-mail address: diana.prata@kcl.ac (D. Prata).
} 
a safeguard against noise or confounder effects.

In the present study, we aimed to test the effect of the PGC2-SZ PRS on white matter microstructure integrity, using FA and MD as proxies, in healthy individuals, SZ, BD and SZ/BD relatives' (REL) samples. Considering that both a high SZ PRS (Ruderfer et al., 2014; Tesli et al., 2014) a decreased FA (Ambrosi et al., 2013; Hummer et al., 2016; Kanaan et al., 2017; Subramaniam et al., 2017; Viher et al., 2016; Zhuo et al., 2016), and an increased MD, (Kanaan et al., 2017; Squarcina et al., 2017; Zhuo et al., 2016), are associated with SZ and BD, our main hypothesis was that PGC2-SZ PRS would be negatively associated with FA, and positively with MD. In addition, we also examined whether the effects of PGC2-SZ PRS on FA/MD would be different between the different diagnostic groups, since ours and others' previous work, have shown significant genotype by diagnosis effects on these brain measures (Gurung and Prata, 2015; Mallas et al., 2016).

\section{Methods}

DTI and PRS data were selected from a dataset used in previous studies (Allin et al., 2011; Chaddock et al., 2009; Kanaan et al., 2017; Kyriakopoulos et al., 2009; Mallas et al., 2016; Picchioni et al., 2006; Shergill et al., 2007) at the Institute of Psychiatry, Psychology and Neuroscience (IoPPN), King's College London. The selected 141 subjects were divided in four different diagnostic groups: SZ $(\mathrm{n}=21)$, BD $(\mathrm{n}=25), \mathrm{BD} / \mathrm{SZ}$ relatives $(\mathrm{BD} / \mathrm{SZ} \mathrm{REL} ; \mathrm{n}=27)$ and healthy controls $(\mathrm{n}=68)$. Demographics statistical tests using IBM SPSS 25 (IBM Corp, 2017) showed BD to be significantly older than healthy individuals (Mann-Whitney U $=528.500$, p-value $=0.005$ ); and REL's IQ z-scores to be higher than SZ's ( $\mathrm{U}=145.500$; $\mathrm{p}$-value $=0.004)$, and higher than healthy individuals $(U=561.000 ; p$-value $=0.003)$. As expected, PRS was associated with diagnosis $(\mathrm{F}=4.575$, $\mathrm{p}$-value $=0.004$; see Fig. 1$)$, with PRS being significantly higher in SZ than HC (Tukey's HSD mean difference $=0.844$, $\mathrm{p}$-value $=0.003$; see Fig. 1), but not significantly correlated with any of the demographic variables. Chlorpromazine equivalents (CPZ) were also calculated for the patients groups for descriptive reasons, and for its ascertainment as a confounding factor. As CPZ was not statistically significantly associated with the PRS (Pearson's correlation $=0.169, \mathrm{p}$-value $=0.441$, among both patient groups) in the present sample, nor with white matter microstructure (namely FA) in a largely overlapping sample (Kanaan et al., 2009) (which has later been independently reinforced (Wang et al., 2013)), antipsychotic medication was herein not considered a potential confounding, nor a relevant nuisance, factor. For further demographics statistics, see Supplementary Table 1.

DNA was extracted, processed and genotyped as we previously described (Vassos et al., 2017). The PGC2-SZ PRS was calculated for each participant as the sum of the risk single nucleotide polymorphisms (SNPs) weighted by the logarithm of odds ratio of their respective association with SZ in the PGC2 meta-analysis (Ripke et al., 2014), using the set of statistically significant SNPs with the highest case-control explanatory power which we have previously determined in an independent sample (Vassos et al., 2017).

MRI data was acquired as we previously described (Mallas et al., 2016). Preprocessing of the diffusion MRI images was made using FSL version 5.0.8 (Jenkinson et al., 2012), and included eddy currents distortions correction and brain-extraction with a threshold of 0.2 to ensure a balance between complete scalp removal and inappropriate erosion of brain tissue. FA and MD images were created by fitting a tensor model to the raw diffusion data.

Voxel-wise statistical analysis of FA and MD data was carried out using TBSS (Smith et al., 2006) (Jenkinson et al., 2012) and then fed into a general linear model (GLM) (Smith et al., 2006), both in FSL version 5.0.8. Main effects of PGC2-SZ PRS on FA/MD, followed a regression design (with diagnosis as a covariate of no interest), and PGC2SZ PRS x diagnosis interaction an ANCOVA, with a permutation-based approach (Smith and Nichols, 2009). Age and gender were added to the models as they showed a predicted significant large effect on FA or MD (namely, corpus callosum ( $p=0.002)$, cingulum $(p=0.047)$ and superior longitudinal fasciculus ( $\mathrm{p}=0.049$ ); and gender on MD in the anterior thalamic radiation $(\mathrm{p}=0.049)$ ).

Statistical significance was considered when effects surpassed the threshold free cluster enhancement (TFCE)-correction at a p-value < 0.05 , while trends were considered so when showing a TFCE-uncorrected p-value $<0.01$, following standard practice (Mallas et al., 2016; Subramaniam et al., 2017; Viher et al., 2016). The 10 largest clusters of each contrast are reported in Table 1, for conciseness; with the extended list in Supplementary Table 3. For each effect, the $\mathrm{R}^{2}$ effect size was calculated based on the t-statistics value of the peak voxel

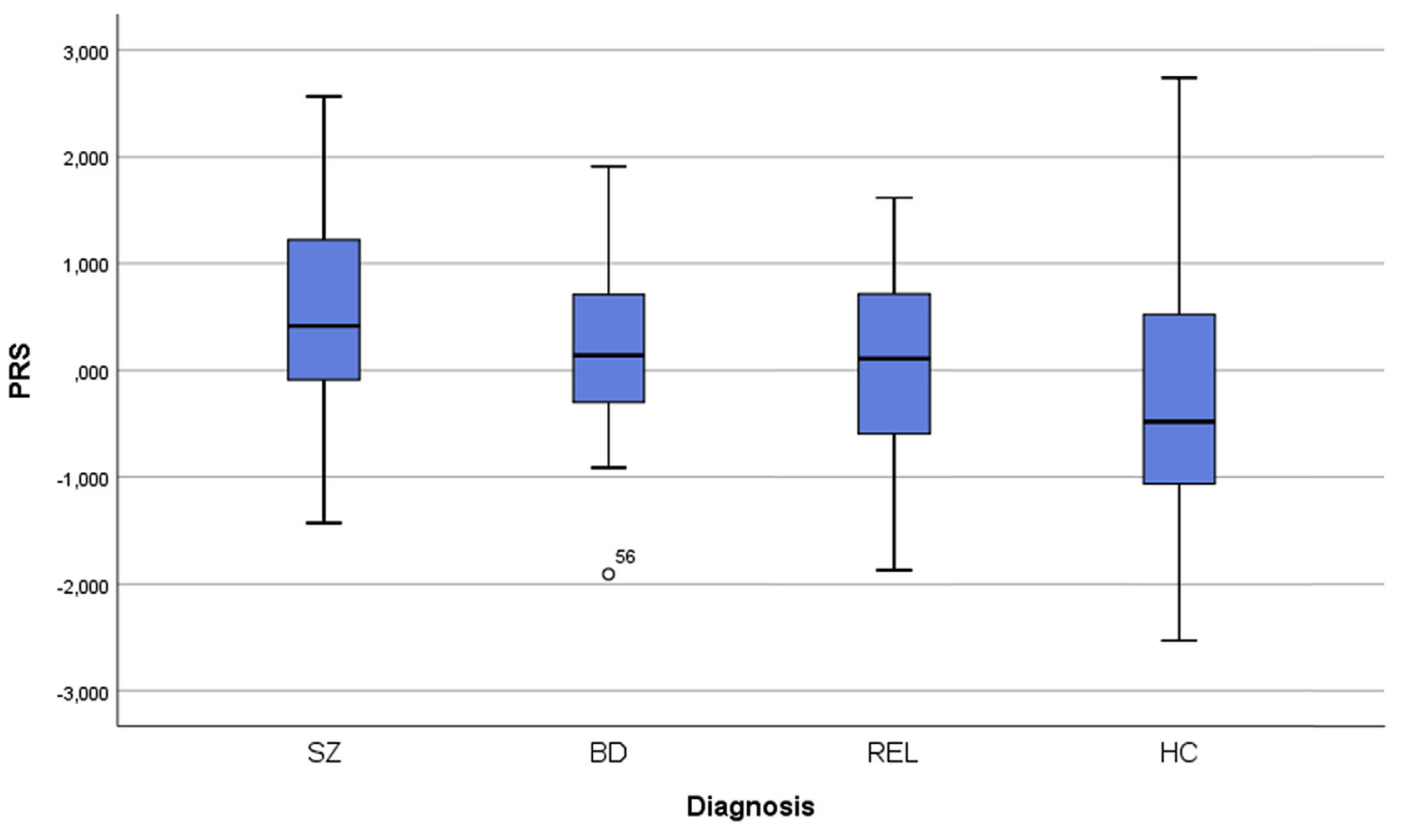

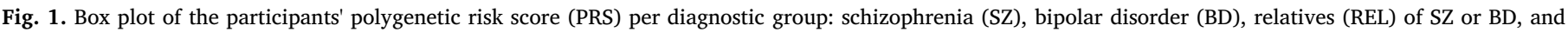
healthy controls (HC). 
Table 1

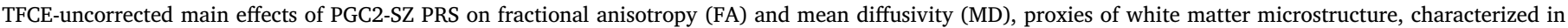

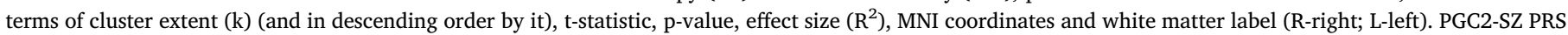
by Diagnosis interactions are reported in Supplementary Table 2.

\begin{tabular}{|c|c|c|c|c|c|c|c|}
\hline \multirow[t]{2}{*}{ Cluster extent (k) } & \multirow[t]{2}{*}{ t-statistic } & \multirow[t]{2}{*}{ p-value } & \multirow[t]{2}{*}{$\mathrm{R}^{2}$} & \multicolumn{3}{|c|}{ Peak MNI coordinates } & \multirow[t]{2}{*}{ Cluster Label } \\
\hline & & & & $\mathrm{x}\{\mathrm{mm}\}$ & white matter $\{\mathrm{mm}\}$ & $\mathrm{z}\{\mathrm{mm}\}$ & \\
\hline \multicolumn{8}{|c|}{ Main effect of SZ PRS on FA } \\
\hline \multicolumn{8}{|c|}{ Positive correlation } \\
\hline 3 & 2.239 & 0.007 & 0.035 & 68 & 182 & 79 & Anterior thalamic radiation $\mathrm{R}$ \\
\hline \multicolumn{8}{|c|}{ Negative correlation } \\
\hline 140 & 0.598 & 0.003 & 0.003 & 65 & 113 & 41 & Cingulum $\mathrm{R}$ \\
\hline 50 & 1.649 & 0.004 & 0.019 & 44 & 70 & 78 & Inferior longitudinal fasciculus $\mathrm{R}$ \\
\hline 36 & 1.747 & 0.006 & 0.022 & 79 & 109 & 140 & Corpus callosum $\mathrm{R}$ \\
\hline 23 & 1.507 & 0.007 & 0.016 & 106 & 48 & 81 & Cingulum L \\
\hline 23 & 2.016 & 0.005 & 0.029 & 36 & 80 & 58 & Stria terminalis $\mathrm{R}$ \\
\hline 23 & 0.71 & 0.005 & 0.004 & 133 & 60 & 93 & Superior longitudinal fasciculus L \\
\hline 23 & 1.215 & 0.006 & 0.011 & 53 & 48 & 95 & Inferior longitudinal fasciculus $\mathrm{R}$ \\
\hline 16 & 1.017 & 0.005 & 0.007 & 73 & 117 & 137 & Corpus callosum $\mathrm{R}$ \\
\hline 15 & 1.349 & 0.006 & 0.013 & 81 & 49 & 93 & Cingulum R \\
\hline 12 & 1.423 & 0.008 & 0.015 & 39 & 75 & 68 & Superior longitudinal fasciculus $\mathrm{R}$ \\
\hline 12 & 2.377 & 0.006 & 0.04 & 58 & 122 & 97 & Superior longitudinal fasciculus $\mathrm{R}$ \\
\hline \multicolumn{8}{|c|}{ Main effect of SZ PRS on MD } \\
\hline \multicolumn{8}{|c|}{ Positive correlation } \\
\hline 5 & 2.982 & 0.001 & 0.061 & 97 & 109 & 133 & Corticopontine tract $\mathrm{L}$ \\
\hline 4 & 2.735 & 0.005 & 0.052 & 66 & 80 & 48 & Middle cerebellar peduncle $\mathrm{R}$ \\
\hline 1 & 2.374 & 0.01 & 0.04 & 118 & 167 & 65 & Inferior fronto-occipital fasciculus $\mathrm{L}$ \\
\hline 1 & 2.873 & 0.002 & 0.057 & 67 & 84 & 105 & Posterior corona radiata $\mathrm{R}$ \\
\hline \multicolumn{8}{|c|}{ Negative correlation } \\
\hline 12 & 2.857 & 0.002 & 0.056 & 90 & 73 & 48 & Inferior cerebellar peduncle \\
\hline
\end{tabular}

which determines, along with cluster size, the TFCE corrected p-valueLastly, to determine the white matter regions/tracts the Johns Hopkins University ICBM-DTI-81 white-matter label atlas (https://fsl. fmrib.ox.ac.uk/fsl/fslwiki/Atlases) was used. If no region was retrieved, labelling was carried out manually using the MRI Atlas of Human white matter (Mori et al., 2005). Further detail on methods are presented as supplementary information.

\section{Results}

\subsection{Main effect of PGC2-SZ PRS on fractional anisotropy and mean diffusivity}

The main effects of PRS on either FA or MD were not statistically significant. However, negative trends were found whereby PRS was correlated with FA in five regions, of which the right cingulum showed the largest cluster, and the only positive trend of PRS on FA was found in the anterior thalamic radiation (see Table 1 and Fig. 2). On MD, positive trends were seen in four equality small clusters/regions, and one negative trend in the inferior cerebellar peduncle (see Table 1 and Fig. 3).

\subsection{PGC2-SZ PRS $x$ diagnosis interaction on fractional anisotropy and mean diffusivity}

No statistically significant PRS $\mathrm{x}$ diagnosis interactions on FA or MD were found. Most interactions trends showed similar (small) cluster and effects sizes as the above main effects, except two distinguished by their cluster sizes (albeit their effect sizes explained at maximum of $5 \%$ of FA variance): the PRS had a stronger positive correlation with FA on BD than on healthy individuals, and than on SZ: cluster sizes were quite large reaching 3957 voxels in the middle cerebellar peduncle and 1252 in the corticopontine tract, respectively (see Supplementary Table 2).

PRS-FA/MD correlation plots for the peak coordinate of the most TFCE-significant clusters, for each effect described in Table, can be found in Supplementary Figs. 1-4.

\section{Discussion}

No significant main effects of the PGC2-SZ PRS, or PGC2-SZ PRS by diagnosis interactions, were found on MD or FA. However, both positive and negative TFCE-uncorrected trends (at p-value $<0.01$ ) were found. Main effects, either positive or negative, of PRS on FA were small (in terms of effect size, ranging $0.3-4 \%$ ). The (expected) negative main effect trends on FA showed one to two orders of magnitude larger cluster sizes reaching 140 voxels in the right cingulum, in comparison with the (unexpected) positive trends ( 3 voxels). This region's FA shows high heritability (30-70\%) (Vuoksimaa et al., 2017) and its white matter alterations have been consistently detected in SZ in previous work (Ellison-Wright and Bullmore, 2009; Knochel et al., 2012; Lener et al., 2015), suggesting it may be implicated in SZ onset. The largest (in terms of effect size) PRS trend on FA was for a negative correlation explaining $4 \%$ of variance in the right superior longitudinal fasciculus. Generally one order of magnitude larger than on FA, but still small, were the effects on MD (explaining 4-6\% of variance): positive trends were seen in four equally small clusters/regions, and one negative trend in the inferior cerebellar peduncle within a cluster of 12 voxels (see Table 1). Regarding diagnosis-dependent effects of PRS, PRS showed a non-significant higher correlation trend for BD than for healthy individuals or SZ, the clusters being 2-3 orders of magnitude higher than those of the main effects but the effect size being equally small $(0.5-5 \%$; see Supplementary Table 2).

To put it in perspective, we found the PGC2-SZ PRS to explain a smaller proportion of the variance of FA/MD, than of the observed scale case-control status (9.2\%) (Vassos et al., 2017), or than of SZ liability (7\%) (Ripke et al., 2014). However its effect magnitude on these brain structure phenotypes was closer to what we found on general cognition (2.7\%) (Toulopoulou et al., 2019). This challenges the expectation that penetrance of genetic factors of these complex illnesses on their white matter microstructure or cognitive endophenotypes should be larger than on the illnesses themselves (Iacono, 2018). In the latter cognition study, we have also found more than a quarter of the genetic influence on SZ liability to be mediated through cognition-related paths that were independent of the PRS. Similarly two thirds of the genetic effects on SZ 

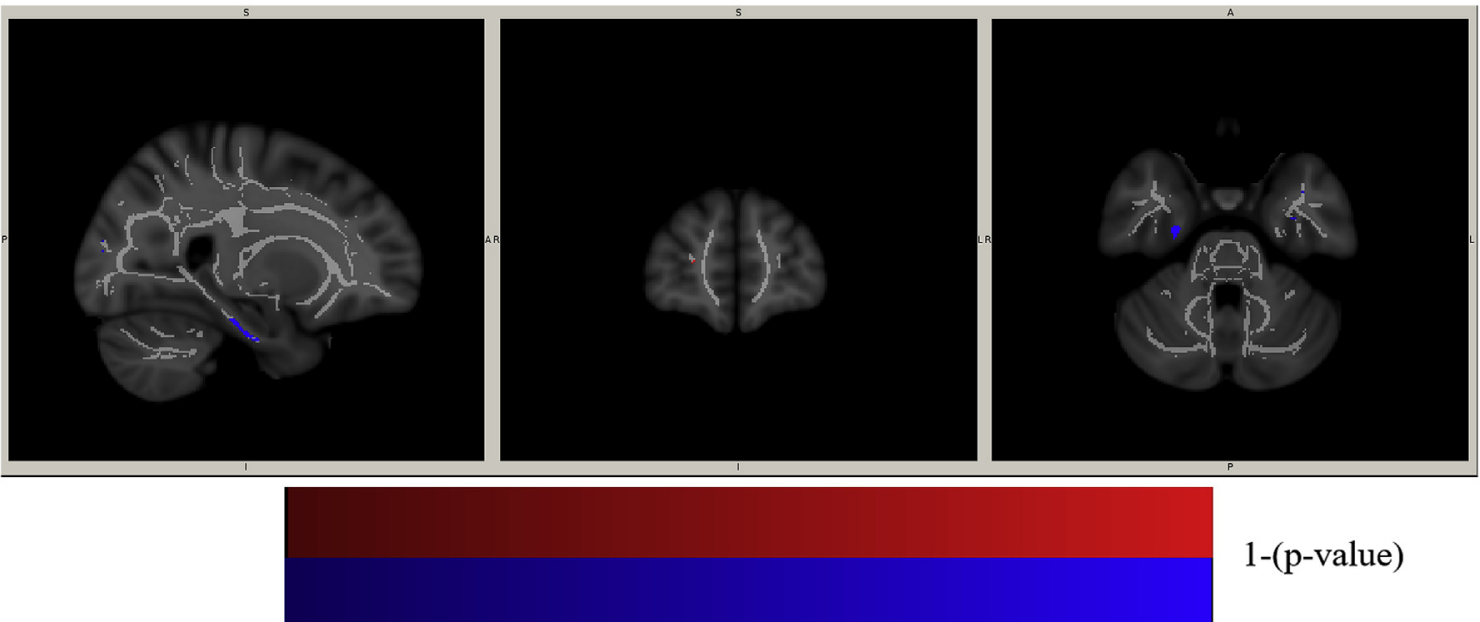

$1-(\mathrm{p}$-value)

0

1

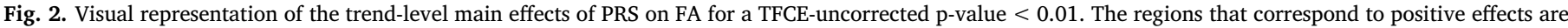

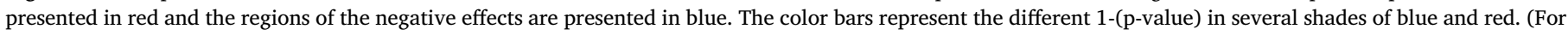
interpretation of the references to color in this figure legend, the reader is referred to the Web version of this article.)

were independent of the PRS (Toulopoulou et al., 2019). Indeed, contrary to the expectations earlier put on endophenotypes, they do not seem to be useful for gene discovery. However, they remain useful for identifying pathways and mechanisms to disease (from gene to brain); and to validate the statistical and clinical usefulness of genetic markers (such as the PRS) previously associated to SZ to predict clinical outcomes (from onset, to diagnosis, prognosis and treatment response). In particular, genetic markers (more than neuroimaging ones) entail the potential to be clinically useful biomarkers due to their screening speed, ease and cost-effectiveness; even though these are still to be found since our last review on the matter (Prata et al., 2014).

One of the possible reasons for the lack of statistical significance is that our sample size was insufficient to detected an effect, on brain structure, of a PRS which, in its present formula, still explains, albeit robustly and well replicated, a small proportion of SZ risk (7-9\%) (Ripke et al., 2014; Vassos et al., 2017). Notably, the only other study focusing on the influence of the PGC2-SZ PRS on white matter microstructure (FA/MD), simultaneous to ours, has also not found a significant effect of SZ PRS on FA/MD, even with an approximately 6 times larger (UK Biobank) sample (Reus et al., 2017); even though that study might have had other limitations given the highly clinically mixed sample, we did not. However, insufficient power may also arise from the incomplete predictive power of the PGC2 SZ PRS score (which $\sim 7 \%$ of the variance in the liability scale currently explained (Ripke et al., 2014)), or, rather, of each of the individual genetic variations reported in the PGC. Given the high heritability of SZ and BD which suggests that genetic factors pose a major contribution to the inherent brain alterations, and the high heritability of some of these well-known brain alterations such as in FA and MD (Vuoksimaa et al., 2017), it is possible that the genetic risk variants that contribute most to the disorders, and to white matter alterations, are either not the same (i.e. different genetic variants affect white matter and SZ/BD risk, via separate pathways), or are not common in the population (i.e. have not been detected by GWAS SNP-based outputs). If the later, alternative genotyping methods, e.g. sequencing, or statistical methods incorporating rare variants such as copy number variants in the PRS, may
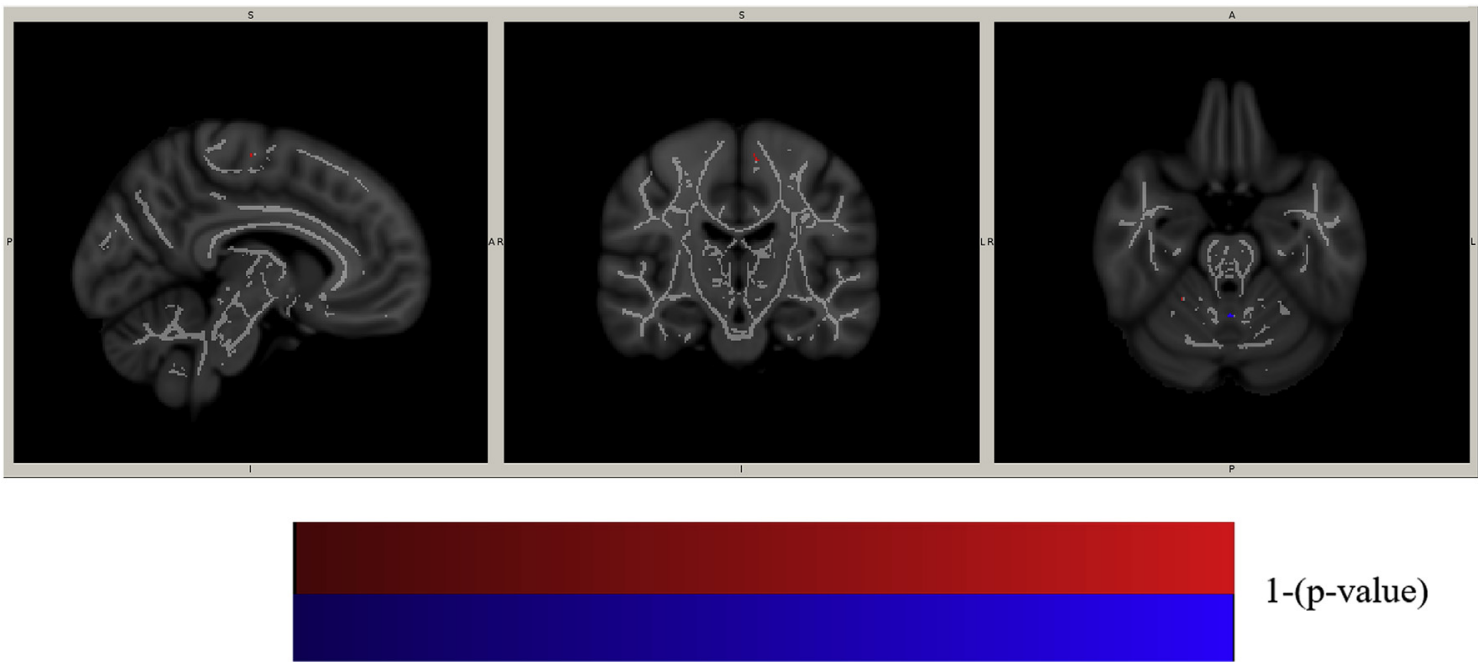

$1-(\mathrm{p}-\mathrm{value})$

0

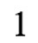

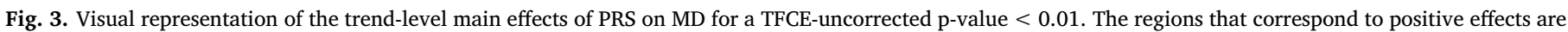

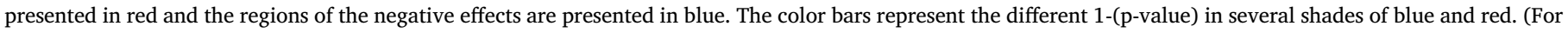
interpretation of the references to color in this figure legend, the reader is referred to the Web version of this article.) 
be necessary.

Lastly, our null hypothesis could also be harder to reject if there is a higher association of MD/FA white matter changes with positive symptoms in SZ, and of the PGC2-SZ PRS with negative symptoms. Indeed, white matter FA reductions have been associated with positive symptoms' decrease after antipsychotics, at least in fronto-temporolimbic regions (Cho et al., 2018); and the PRS (as herein, based on PGC2 variants) has been associated specifically with negative symptoms as blunted affect and emotional withdrawal (Fanous et al., 2012; Jones et al., 2016). In conclusion, our findings suggest we cannot exclude the null hypothesis that the PGC2-SZ PRS does not explain brain FA or MD variability in healthy, SZ, BD or their relatives' populations. Although a higher PRS for SZ may lead to impaired white matter integrity and poorer neural connectivity, the present test would need to be replicated in a more powerful sample, so the detected trends are confirmed.

\section{Author contributions}

BS ran the neuroimaging and statistical analysis and drafted the manuscript; DP acquired some of the genetic data, revised and co-wrote the manuscript, designed and supervised the overall work; EV and EB provided the PRS; SS, CM, TT, SK and FK provided the imaging data; RM supervised genetic and neuroimaging data collection; and HF cosupervised the neuroimaging analysis.

\section{Declaration of competing interest}

None of the authors declare any conflict of interest.

\section{Acknowledgements}

This study represents independent research partially funded by the National Institute for Health Research (NIHR) Biomedical Research Centre at South London and Maudsley NHS Foundation Trust and King's College London. The views expressed are those of the authors and not necessarily those of the NHS, the NIHR or the Department of Health. DP was supported, during data collection, by Fundação para a Ciência e Tecnologia (FCT) fellowship SFRH/BD/12394/2003 and NIHR grant PDF-2010-03-047, and during analysis and write-up, by an European Commission Marie Curie Career Integration grant (FP7-PEOPLE-2013CIG-631952), FCT grants (IF/00787/2014, LISBOA-01-0145-FEDER030907 and DSAIPA/DS/0065/2018), an iMM Lisboa Director's Fund Breakthrough Idea Grant (2016), and the Bial Foundation Psychophysiology Grant (2016, Ref. 292/16), and is co-founder of NeuroPsyAI, Ltd. None of the authors declare any conflict of interest.

\section{Appendix A. Supplementary data}

Supplementary data to this article can be found online at https:// doi.org/10.1016/j.jpsychires.2019.11.011.

\section{References}

Allin, M.P., Kontis, D., Walshe, M., Wyatt, J., Barker, G.J., Kanaan, R.A., McGuire, P., Rifkin, L., Murray, R.M., Nosarti, C., 2011. White matter and cognition in adults who were born preterm. PLoS One 6, e24525. https://doi.org/10.1371/journal.pone. 0024525.

Ambrosi, E., Rossi-Espagnet, M.C., Kotzalidis, G.D., Comparelli, A., Del Casale, A., Carducci, F., Romano, A., Manfredi, G., Tatarelli, R., Bozzao, A., Girardi, P., 2013. Structural brain alterations in bipolar disorder II: a combined voxel-based morphometry (VBM) and diffusion tensor imaging (DTI) study. J. Affect. Disord. 150, 610-615. https://doi.org/10.1016/j.jad.2013.02.023.

Chaddock, C.A., Barker, G.J., Marshall, N., Schulze, K., Hall, M.H., Fern, A., Walshe, M., Bramon, E., Chitnis, X.A., Murray, R., McDonald, C., 2009. White matter microstructural impairments and genetic liability to familial bipolar I disorder. Br. J. Psychiatry 194, 527-534. https://doi.org/10.1192/bjp.bp.107.047498.

Cho, S.J., Kim, M.-K., Bang, S.Y., Bang, M., Lee, S.-H., 2018. White matter integrity associated with severity reductions in positive symptoms after amisulpride treatment in drug-free patients with schizophrenia. Neurosci. Lett. 685, 131-136. https://doi.org/ 10.1016/j.neulet.2018.08.036.

Craddock, N., Owen, M.J., 2005. The beginning of the end for the Kraepelinian dichotomy. Br. J. Psychiatry 186, 364-366. https://doi.org/10.1192/bjp.186.5.364.

Ellison-Wright, I., Bullmore, E., 2009. Meta-analysis of diffusion tensor imaging studies in schizophrenia. Schizophr. Res. 108, 3-10. https://doi.org/10.1016/j.schres.2008.11. 021.

Fanous, A.H., Zhou, B., Aggen, S.H., Bergen, S.E., Amdur, R.L., Duan, J., Sanders, A.R., Shi, J., Mowry, B.J., Olincy, A., Amin, F., Cloninger, C.R., Silverman, J.M., Buccola, N.G., Byerley, W.F., Black, D.W., Freedman, R., Dudbridge, F., Holmans, P.A., Ripke, S., Gejman, P.V., Kendler, K.S., Levinson, D.F., 2012. Genome-wide association study of clinical dimensions of schizophrenia: polygenic effect on disorganized symptoms. Am. J. Psychiatry 169, 1309-1317. https://doi.org/10.1176/appi.ajp.2012. 12020218.

Gurung, R., Prata, D.P., 2015. What is the impact of genome-wide supported risk variants for schizophrenia and bipolar disorder on brain structure and function? A systematic review. Psychol. Med. 45. https://doi.org/10.1017/S0033291715000537.

Hummer, T.A., Francis, M.M., Vohs, J.L., Liffick, E., Mehdiyoun, N.F., Breier, A., 2016. Characterization of white matter abnormalities in early-stage schizophrenia. Early Interv Psychiatry. https://doi.org/10.1111/eip.12359.

Iacono, W.G., 2018. Endophenotypes in psychiatric disease: prospects and challenges. Genome Med. 10, 11. https://doi.org/10.1186/s13073-018-0526-5.

IBM Corp, 2017. IBM SPSS Statistics for Windows.

Jenkinson, M., Beckmann, C.F., Behrens, T.E., Woolrich, M.W., Smith, S.M., 2012. FSL. Neuroimage 62, 782-790. https://doi.org/10.1016/j.neuroimage.2011.09.015.

Jones, H.J., Stergiakouli, E., Tansey, K.E., Hubbard, L., Heron, J., Cannon, M., Holmans, P., Lewis, G., Linden, D.E., Jones, P.B., Davey Smith, G., O'Donovan, M.C., Owen, M.J., Walters, J.T., Zammit, S., 2016. Phenotypic manifestation of genetic risk for schizophrenia during adolescence in the general population. JAMA Psychiatry 73, 221-228. https://doi.org/10.1001/jamapsychiatry.2015.3058.

Kanaan, R., Barker, G., Brammer, M., Giampietro, V., Shergill, S., Woolley, J., Picchioni, M., Toulopoulou, T., McGuire, P., 2009. White matter microstructure in schizophrenia: effects of disorder, duration and medication. Br. J. Psychiatry. https://doi. org/10.1192/bjp.bp.108.054320.

Kanaan, R.A., Picchioni, M.M., McDonald, C., Shergill, S.S., McGuire, P.K., 2017. White matter deficits in schizophrenia are global and don't progress with age. Aust. N. Z. J. Psychiatr. 51, 1020-1031. https://doi.org/10.1177/0004867417700729.

Knochel, C., O'Dwyer, L., Alves, G., Reinke, B., Magerkurth, J., Rotarska-Jagiela, A., Prvulovic, D., Hampel, H., Linden, D.E.J., Oertel-Knochel, V., 2012. Association between white matter fiber integrity and subclinical psychotic symptoms in schizophrenia patients and unaffected relatives. Schizophr. Res. 140, 129-135. https://doi. org/10.1016/j.schres.2012.06.001.

Kyriakopoulos, M., Perez-Iglesias, R., Woolley, J.B., Kanaan, R.A., Vyas, N.S., Barker, G.J., Frangou, S., McGuire, P.K., 2009. Effect of age at onset of schizophrenia on white matter abnormalities. Br. J. Psychiatry 195, 346-353. https://doi.org/10. 1192/bjp.bp.108.055376.

Lener, M.S., Wong, E., Tang, C.Y., Byne, W., Goldstein, K.E., Blair, N.J., Haznedar, M.M., New, A.S., Chemerinski, E., Chu, K.-W., Rimsky, L.S., Siever, L.J., Koenigsberg, H.W., Hazlett, E.A., 2015. White matter abnormalities in schizophrenia and schizotypal personality disorder. Schizophr. Bull. 41, 300-310. https://doi.org/10.1093/schbul/ sbu093.

Mallas, E.-J., Carletti, F., Chaddock, C.A., Woolley, J., Picchioni, M.M., Shergill, S.S., Kane, F., Allin, M.P.G., Barker, G.J., Prata, D.P., 2016. Genome-wide discovered psychosis-risk gene ZNF804A impacts on white matter microstructure in health, schizophrenia and bipolar disorder. PeerJ. https://doi.org/10.7717/peerj.1570. 2016.

Mori, S., Wakana, S., van Zijl, P., Nagae-Poetcher, L.M., 2005. MRI Atlas of Human White Matter, first ed. Elsevier Science.

Picchioni, M.M., Toulopoulou, T., Landau, S., Davies, N., Ribchester, T., Murray, R.M., 2006. Neurological abnormalities in schizophrenic twins. Biol. Psychiatry 59, 341-348. https://doi.org/10.1016/j.biopsych.2005.07.007.

Prata, D., Mechelli, A., Kapur, S., 2014. Clinically meaningful biomarkers for psychosis: a systematic and quantitative review. Neurosci. Biobehav. Rev. https://doi.org/10. 1016/j.neubiorev.2014.05.010.

Reus, L.M., Shen, X., Gibson, J., Wigmore, E., Ligthart, L., Adams, M.J., Davies, G., Cox, S.R., Hagenaars, S.P., Bastin, M.E., Deary, I.J., Whalley, H.C., McIntosh, A.M., 2017. Association of polygenic risk for major psychiatric illness with subcortical volumes and white matter integrity in UK Biobank. Sci. Rep. 7, 42140. https://doi.org/10. 1038/srep42140.

Ripke, S., Neale, B.M., Corvin, A., Walters, J.T.R., Farh, K.H., Holmans, P.A., Lee, P., Bulik-Sullivan, B., Collier, D.A., Huang, H., Pers, T.H., Agartz, I., Agerbo, E., Albus, M., Alexander, M., Amin, F., Bacanu, S.A., Begemann, M., Belliveau, R.A., Bene, J., Bergen, S.E., Bevilacqua, E., Bigdeli, T.B., Black, D.W., Bruggeman, R., Buccola, N.G., Buckner, R.L., Byerley, W., Cahn, W., Cai, G., Campion, D., Cantor, R.M., Carr, V.J., Carrera, N., Catts, S.V., Chambert, K.D., Chan, R.C.K., Chen, R.Y.L., Chen, E.Y.H., Cheng, W., Cheung, E.F.C., Chong, S.A., Cloninger, C.R., Cohen, D., Cohen, N., Cormican, P., Craddock, N., Crowley, J.J., Curtis, D., Davidson, M., Davis, K.L., Degenhardt, F., Del Favero, J., Demontis, D., Dikeos, D., Dinan, T., Djurovic, S., Donohoe, G., Drapeau, E., Duan, J., Dudbridge, F., Durmishi, N., Eichhammer, P., Eriksson, J., Escott-Price, V., Essioux, L., Fanous, A.H., Farrell, M.S., Frank, J., Franke, L., Freedman, R., Freimer, N.B., Friedl, M., Friedman, J.I., Fromer, M., Genovese, G., Georgieva, L., Giegling, I., Giusti-Rodríguez, P., Godard, S., Goldstein, J.I., Golimbet, V., Gopal, S., Gratten, J., De Haan, L., Hammer, C., Hamshere, M.L., Hansen, M., Hansen, T., Haroutunian, V., Hartmann, A.M., Henskens, F.A., Herms, S., Hirschhorn, J.N., Hoffmann, P., Hofman, A., Hollegaard, M.V., Hougaard, D.M., Ikeda, M., Joa, I., Julià, A., Kahn, R.S., Kalaydjieva, L., Karachanak-Yankova, S., 
Karjalainen, J., Kavanagh, D., Keller, M.C., Kennedy, J.L., Khrunin, A., Kim, Y., Klovins, J., Knowles, J.A., Konte, B., Kucinskas, V., Kucinskiene, Z.A., KuzelovaPtackova, H., Kähler, A.K., Laurent, C., Keong, J.L.C., Lee, S.H., Legge, S.E., Lerer, B., Li, M., Li, T., Liang, K.Y., Lieberman, J., Limborska, S., Loughland, C.M., Lubinski, J., Lönnqvist, J., Macek, M., Magnusson, P.K.E., Maher, B.S., Maier, W., Mallet, J.,

Marsal, S., Mattheisen, M., Mattingsdal, M., McCarley, R.W., McDonald, C., McIntosh, A.M., Meier, S., Meijer, C.J., Melegh, B., Melle, I., Mesholam-Gately, R.I., Metspalu, A., Michie, P.T., Milani, L., Milanova, V., Mokrab, Y., Morris, D.W., Mors, O., Murphy, K.C., Murray, R.M., Myin-Germeys, I., Müller-Myhsok, B., Nelis, M., Nenadic, I., Nertney, D.A., Nestadt, G., Nicodemus, K.K., Nikitina-Zake, L., Nisenbaum, L., Nordin, A., O'Callaghan, E., O'Dushlaine, C., O'Neill, F.A., Oh, S.Y., Olincy, A., Olsen, L., Van Os, J., Pantelis, C., Papadimitriou, G.N., Papiol, S., Parkhomenko, E., Pato, M.T., Paunio, T., Pejovic-Milovancevic, M., Perkins, D.O., Pietiläinen, O., Pimm, J., Pocklington, A.J., Powell, J., Price, A., Pulver, A.E., Purcell, S.M., Quested, D., Rasmussen, H.B., Reichenberg, A., Reimers, M.A., Richards, A.L., Roffman, J.L., Roussos, P., Ruderfer, D.M., Salomaa, V., Sanders, A.R., Schall, U., Schubert, C.R., Schulze, T.G., Schwab, S.G., Scolnick, E.M., Scott, R.J., Seidman, L.J., Shi, J., Sigurdsson, E., Silagadze, T., Silverman, J.M., Sim, K., Slominsky, P., Smoller, J.W., So, H.C., Spencer, C.C.A., Stahl, E.A., Stefansson, H., Steinberg, S., Stogmann, E., Straub, R.E., Strengman, E., Strohmaier, J., Stroup, T.S., Subramaniam, M., Suvisaari, J., Svrakic, D.M., Szatkiewicz, J.P., Söderman, E., Thirumalai, S., Toncheva, D., Tosato, S., Veijola, J., Waddington, J., Walsh, D., Wang, D., Wang, Q., Webb, B.T., Weiser, M., Wildenauer, D.B., Williams, N.M., Williams, S., Witt, S.H., Wolen, A.R., Wong, E.H.M., Wormley, B.K., Xi, H.S., Zai, C.C., Zheng, X., Zimprich, F., Wray, N.R., Stefansson, K., Visscher, P.M., Adolfsson, R., Andreassen, O.A., Blackwood, D.H.R., Bramon, E., Buxbaum, J.D., Børglum, A.D., Cichon, S., Darvasi, A., Domenici, E., Ehrenreich, H., Esko, T., Gejman, P.V., Gill, M., Gurling, H., Hultman, C.M., Iwata, N., Jablensky, A.V., Jönsson, E.G., Kendler, K.S., Kirov, G., Knight, J., Lencz, T., Levinson, D.F., Li, Q.S., Liu, J., Malhotra, A.K., McCarroll, S.A., McQuillin, A., Moran, J.L., Mortensen, P.B., Mowry, B.J., Nöthen, M.M., Ophoff, R.A., Owen, M.J., Palotie, A., Pato, C.N., Petryshen, T.L., Posthuma, D., Rietschel, M., Riley, B.P., Rujescu, D., Sham, P.C., Sklar, P., St Clair, D., Weinberger, D.R., Wendland, J.R., Werge, T., Daly, M.J., Sullivan, P.F., O'Donovan, M.C., 2014. Biological insights from 108 schizophrenia-associated genetic loci. Nature 511, 421-427. https://doi.org/10.1038/nature13595.

Ruderfer, D.M., Fanous, A.H., Ripke, S., McQuillin, A., Amdur, R.L., Gejman, P.V., O'Donovan, M.C., Andreassen, O.A., Djurovic, S., Hultman, C.M., Kelsoe, J.R., Jamain, S., Landen, M., Leboyer, M., Nimgaonkar, V., Nurnberger, J., Smoller, J.W., Craddock, N., Corvin, A., Sullivan, P.F., Holmans, P., Sklar, P., Kendler, K.S., 2014. Polygenic dissection of diagnosis and clinical dimensions of bipolar disorder and schizophrenia. Mol. Psychiatry 19, 1017-1024. https://doi.org/10.1038/mp.2013. 138.

Shergill, S.S., Kanaan, R.A., Chitnis, X.A., O'Daly, O., Jones, D.K., Frangou, S., Williams, S.C., Howard, R.J., Barker, G.J., Murray, R.M., McGuire, P., 2007. A diffusion tensor imaging study of fasciculi in schizophrenia. Am. J. Psychiatry 164, 467-473. https:// doi.org/10.1176/ajp.2007.164.3.467.

Smith, S.M., Jenkinson, M., Johansen-Berg, H., Rueckert, D., Nichols, T.E., Mackay, C.E., Watkins, K.E., Ciccarelli, O., Cader, M.Z., Matthews, P.M., Behrens, T.E., 2006. Tract- based spatial statistics: voxelwise analysis of multi-subject diffusion data Neuroimage 31, 1487-1505. https://doi.org/10.1016/j.neuroimage.2006.02.024. Smith, S.M., Nichols, T.E., 2009. Threshold-free cluster enhancement: addressing problems of smoothing, threshold dependence and localisation in cluster inference. Neuroimage 44, 83-98. https://doi.org/10.1016/j.neuroimage.2008.03.061.

Squarcina, L., Bellani, M., Rossetti, M.G., Perlini, C., Delvecchio, G., Dusi, N., Barillari, M., Ruggeri, M., Altamura, C.A., Bertoldo, A., Brambilla, P., 2017. Similar white matter changes in schizophrenia and bipolar disorder: a tract-based spatial statistics study. PLoS One 12, e0178089. https://doi.org/10.1371/journal.pone.0178089.

Subramaniam, K., Gill, J., Fisher, M., Mukherjee, P., Nagarajan, S., Vinogradov, S., 2017. White matter microstructure predicts cognitive training-induced improvements in attention and executive functioning in schizophrenia. Schizophr. Res. https://doi. org/10.1016/j.schres.2017.06.062.

Tesli, M., Espeseth, T., Bettella, F., Mattingsdal, M., Aas, M., Melle, I., Djurovic, S., Andreassen, O.A., 2014. Polygenic risk score and the psychosis continuum model. Acta Psychiatr. Scand. 130, 311-317. https://doi.org/10.1111/acps.12307.

Toulopoulou, T., Zhang, X., Cherny, S., Dickinson, D., Berman, K.F., Straub, R.E., Sham, P., Weinberger, D.R., 2019. Polygenic risk score increases schizophrenia liability through cognition-relevant pathways. Brain. https://doi.org/10.1093/brain/ awy279.

Vassos, E., Di Forti, M., Coleman, J., Iyegbe, C., Prata, D., Euesden, J., O'Reilly, P., Curtis, C., Kolliakou, A., Patel, H., Newhouse, S., Traylor, M., Ajnakina, O., Mondelli, V., Marques, T.R., Gardner-Sood, P., Aitchison, K.J., Powell, J., Atakan, Z., Greenwood, K.E., Smith, S., Ismail, K., Pariante, C., Gaughran, F., Dazzan, P., Markus, H.S., David, A.S., Lewis, C.M., Murray, R.M., Breen, G., 2017. An examination of polygenic score risk prediction in individuals with first-episode psychosis. Biol. Psychiatry 81 . https://doi.org/10.1016/j.biopsych.2016.06.028.

Viher, P.V., Stegmayer, K., Giezendanner, S., Federspiel, A., Bohlhalter, S., Vanbellingen, T., Wiest, R., Strik, W., Walther, S., 2016. Cerebral white matter structure is associated with DSM-5 schizophrenia symptom dimensions. Neuroimage Clin 12, 93-99. https://doi.org/10.1016/j.nicl.2016.06.013.

Vuoksimaa, E., Panizzon, M.S., Hagler, D.J., Hatton, S.N., Fennema-Notestine, C., Rinker, D., Eyler, L.T., Franz, C.E., Lyons, M.J., Neale, M.C., Tsuang, M.T., Dale, A.M., Kremen, W.S., 2017. Heritability of white matter microstructure in late middle age: a twin study of tract-based fractional anisotropy and absolute diffusivity indices. Hum. Brain Mapp. https://doi.org/10.1002/hbm.23502.

Wang, Q., Cheung, C., Deng, W., Li, M., Huang, C., Ma, X., Wang, Y., Jiang, L., Sham, P.C., Collier, D.A., Gong, Q., Chua, S.E., McAlonan, G.M., Li, T., 2013. White-matter microstructure in previously drug-naive patients with schizophrenia after 6 weeks of treatment. Psychol. Med. https://doi.org/10.1017/S0033291713000238.

Whalley, H.C., Sprooten, E., Hackett, S., Hall, L., Blackwood, D.H., Glahn, D.C., Bastin, M., Hall, J., Lawrie, S.M., Sussmann, J.E., McIntosh, A.M., 2013. Polygenic risk and white matter integrity in individuals at high risk of mood disorder. Biol. Psychiatry 74, 280-286. https://doi.org/10.1016/j.biopsych.2013.01.027.

Zhuo, C., Ma, X., Qu, H., Wang, L., Jia, F., Wang, C., 2016. Schizophrenia patients demonstrate both inter-voxel level and intra-voxel level white matter alterations. PLoS One 11, e0162656. https://doi.org/10.1371/journal.pone.0162656. 